\title{
Analyzing the Correlation between Seat Selection, Seat Change, and Academic Performance among University Students
}

\author{
Yu Yang ${ }^{1}$, Wei Nie ${ }^{1}$, Wei Zheng ${ }^{1}$, and Chao Qiao ${ }^{1}$ \\ ${ }^{1}$ Affiliation not available
}

September 27, 2020

\begin{abstract}
ABSTRACT: This study investigates the correlation between classroom seating choice and academic performance of college students. We examined this relationship using statistical analysis, and our sample consisted of 142 undergraduate students enrolled in the School of Software at the Nanchang Hangkong University. First, over the course of one semester, we collected data on students' seating choice, their final exam results, and other data on student characteristics. Second, we constructed a seat calculation model and used the Pearson correlation coefficient method to quantitatively analyze the data. We then visually displayed the seat selection process using two types of figures, color gradation figures and box-plots. This allowed us to empirically examine the relationship between seat selection and academic performance, as well as the effect of seat change on academic performance and the characteristics of the trajectory of student seat change. The results show that student performance is correlated with seat location and changes in seat location. In general, students seated closer to the front row performed better academically, as did students who did not change seats very often. Finally, we plotted the students' seat change trajectories to investigate their seating choice patterns. We also conducted follow-up interviews with instructors and students to obtain more information about why the observed patterns emerged. This study has important implications for university teachers interested in improving classroom management and student learning based on classroom seating choices.
\end{abstract}

\section{Hosted file}

Analyzing the Correlation between Seat Selection, Seat Change, and Academic Performance among Universit available at https://authorea.com/users/362245/articles/483467-analyzing-the-correlationbetween-seat-selection-seat-change-and-academic-performance-among-university-students

\section{Hosted file}

Text Document(except figures or tables).pdf available at https://authorea.com/users/ 362245/articles/483467-analyzing-the-correlation-between-seat-selection-seat-changeand-academic-performance-among-university-students

\section{Hosted file}

table.pdf available at https://authorea.com/users/362245/articles/483467-analyzingthe-correlation-between-seat-selection-seat-change-and-academic-performance-amonguniversity-students 

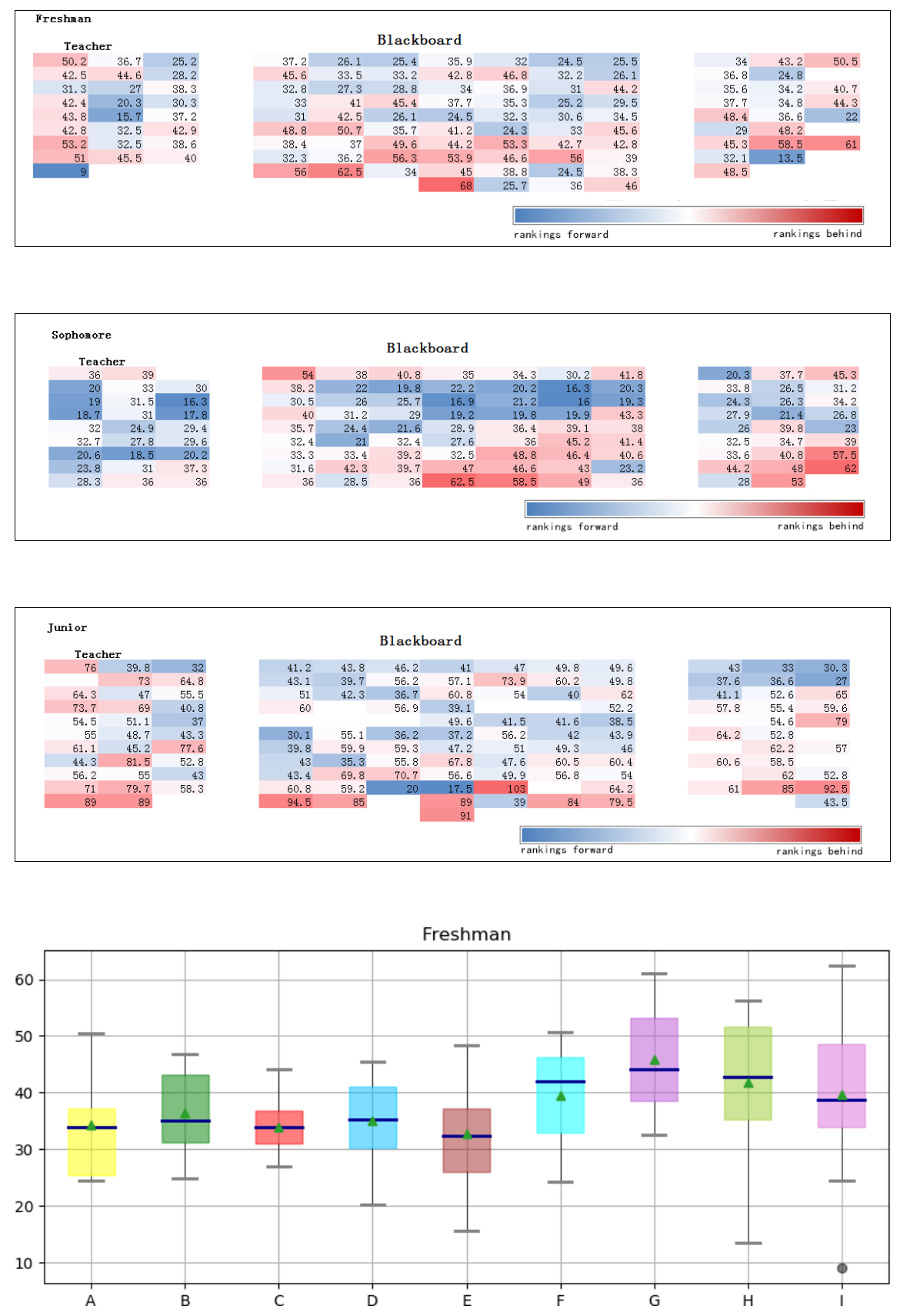

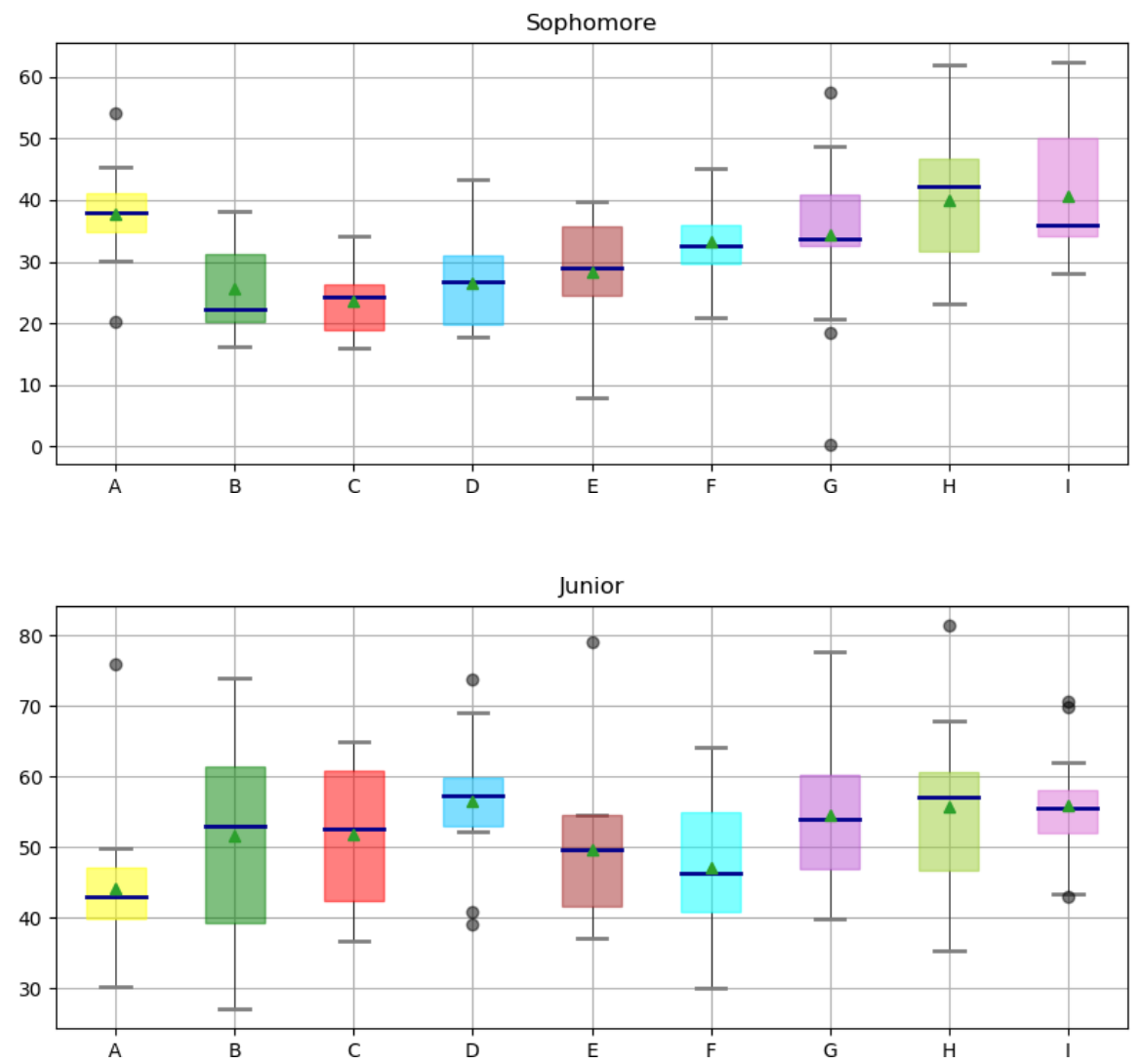

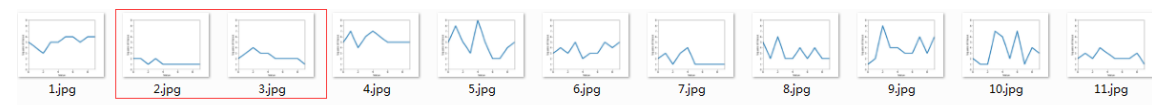

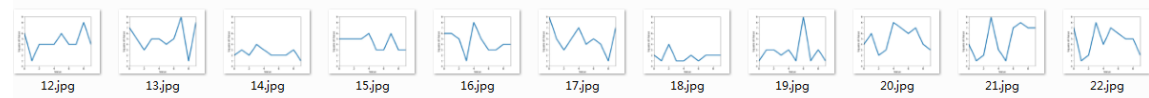

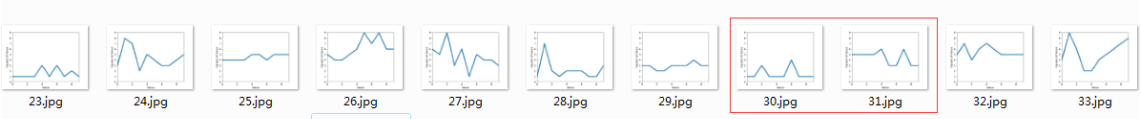

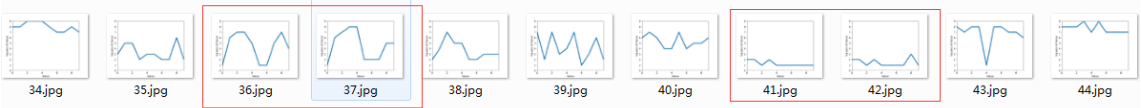

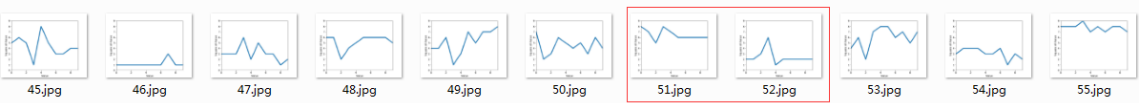

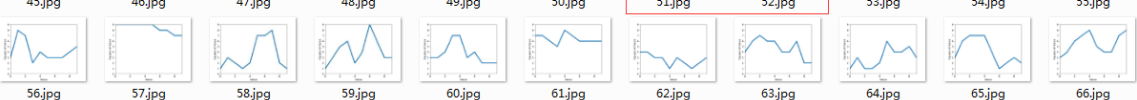
56.jpg 

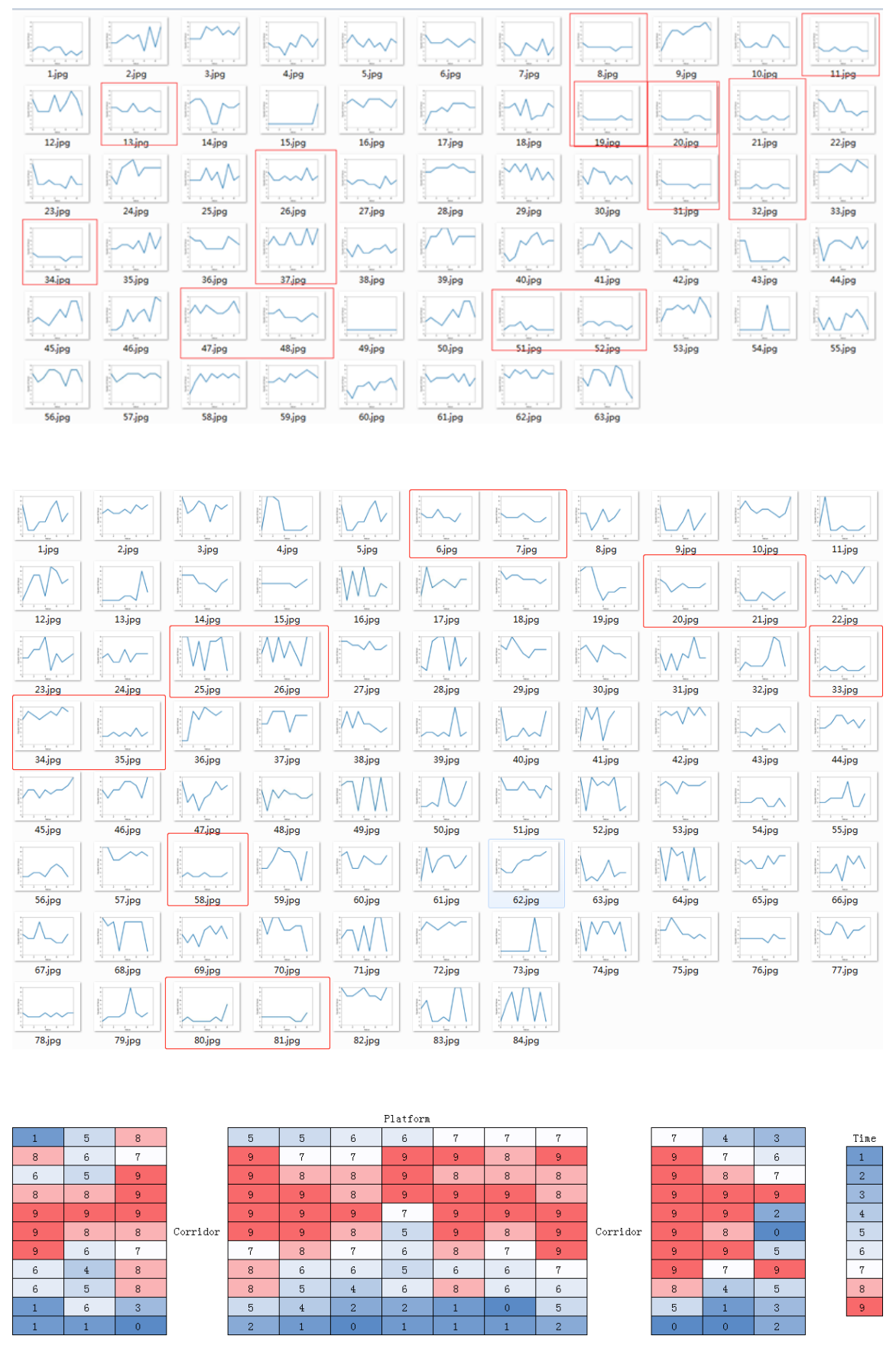